\title{
Qualitative methods and 'the (partly) ineffable' in psychological research on religion and spirituality
}

\author{
Adrian Coyle \\ University of Surrey
}

The full reference for this article is as follows:

Coyle, A. (2008). Qualitative methods and 'the (partly) ineffable' in psychological research on religion and spirituality. Qualitative Research in Psychology, 5(1), 56-67.

\begin{abstract}
About the author
ADRIAN COYLE is a Social Psychologist and Senior Lecturer in the Department of Psychology at the University of Surrey, where he fulfils the role of Director of the MSc Programme in Social Psychology. He has been undertaking qualitative research since the mid-1990s, mostly using interpretative phenomenological analysis, grounded theory and discourse analysis. His research and publications have addressed a wide range of topics, including identity, bereavement, religion and spirituality and various issues within lesbian and gay psychology. With Evanthia Lyons, he is co-editor of Analysing Qualitative Data in Psychology (Sage, 2007).
\end{abstract}

Correspondence: Adrian Coyle, Department of Psychology, University of Surrey, Guildford, Surrey GU2 7XH, UK.

Email: A.Coyle@surrey.ac.uk 


\title{
Qualitative methods and 'the (partly) ineffable' in psychological research on religion and spirituality
}

\author{
Historically, religious and spiritual issues have been marginalized within academic \\ psychology. Even with the advent of the psychology of religion, some important research \\ topics and questions have remained marginalized because of the domain's enthusiastic \\ embrace of a positivist-empiricist framework. This article considers what qualitative \\ methods can offer psychological research on religion and spirituality, focusing on the \\ challenges of exploring religious or spiritual concepts and experiences that may prove \\ difficult to capture in language.
}

Key words: apophatic theology; psychology of religion; qualitative; religion; religious experience; spirituality; spiritual experience; transcendent; transpersonal.

The relationship between psychology and religion/spirituality has fluctuated over time, with their respective constitutive primary discourses being constructed sometimes as complementary or at least capable of being comfortably juxtaposed and at other times as competing and inimical (see Belzen, 2000, for a detailed history). However, as psychology became a socially legitimate and powerful discourse for describing and explaining human minds and behaviours, religion and spirituality were not just consigned to the margins of the discipline but were cast into the domain of 'the inadmissible'. In more recent years, there has been a renewed engagement between psychology and religion/spirituality. In light of this, the present article considers what qualitative methods might contribute to research on psychological aspects of religion and spirituality and examines the challenge of capturing some religious and spiritual concepts and experiences in language. First, however, it is necessary to define and review some key terms.

\section{Defining religion and spirituality}

Defining 'religion' and 'spirituality' is no simple task. Even 'religion', which might appear to be the more concrete term, has evaded attempts to define it satisfactorily and in a way that achieves scholarly consensus. One useful response is that of Loewenthal (1995) who offered a definition by describing several beliefs shared by the major religious traditions, namely a belief in the existence of a non-material (spiritual) reality, a belief that the purpose of life is to increase harmony in the world by doing good and avoiding evil and, in monotheistic religions, a belief that the source of existence (God) is also the source of moral directives. Furthermore, she noted that all religions involve and depend on social and institutional organization for communicating these ideas.

Recent decades have seen a shift away from religion and towards spirituality - something that has been termed a spiritual or spirituality 'revolution' (Tacey, 2004; Woodhead \& Heels, 2004). This has been linked to a 'subjective turn' in the Western world, that is, a turn away from external/'objective’ roles, duties and obligations in shaping lives and towards subjective experiences. Claims about a shift to spirituality relate primarily to Western Christianity and exceptions can readily be found. However, what is posited is that, as institutional, organized religion loses its appeal (evidenced by the dwindling number of people attending places of worship), there has been a (nonparallel) development of less formal, more personal, fragmented spiritualities and spiritually-based practices, often drawing upon or connected to Eastern, 
mystical, esoteric, shamanic and pagan traditions. This has occurred alongside the development of a cultural fear and panic about one particular religion - Islam - in the West.

When we talk of a shift towards 'spirituality', what we mean by this term can be difficult to define. Within psychological literature, it is possible to identify (at least) nine dimensions in the definitions of 'spirituality' offered by various writers (for example, see Elkins et al., 1988; Emmons, 1999; Gorsuch \& Miller, 1999; Zinnbauer et al., 1997). These relate to meaning and purpose in life; a sense of mission or calling in life; a transcendent dimension involving external and internal factors such as deities, spirits, inner guides or higher selves; a belief in the sacredness of life; an emphasis on wholeness and connectedness; the notion of an essential and perhaps eternal soul; the idea of a spiritual journey or path; a belief that pain and suffering are an inescapable part of life and may be meaningful; and a belief in personal transformation. Some definitions seem to offer new terminology and content for concepts that are well developed in psychology, philosophy and psychotherapy, such as the focus on meaning and purpose in life. Yet, as Smith (2006) notes, the meaning and purpose sought within these definitions of spirituality lie beyond the material and sometimes beyond the self - dimensions that may lie outside the standard frames of reference of psychology and some domains of philosophy and psychotherapy. Likewise, the related concept of 'the transpersonal' has been said to lie beyond our usual, individual, rational ways of relating to the world. However, Rowan (2003: 222) differentiates the transpersonal from spirituality on the grounds that 'the divine, the numinous, the sacred, the holy' are not the sine qua non of spirituality in the way they are for the transpersonal. It is worth noting, though, that such views have been said to represent a misconception that spirituality and related domains have to be focused on the 'esoteric' rather than on material and practical concerns (Eagleton, 2007).

A final key concept that needs to be considered is religious or spiritual experience. In definitions of such experiences, Watts (2002) notes that sometimes emphasis is placed on the distinctive phenomenological quality of the experience or on the sorts of spiritual realities that are the objects of the experience. At other times, emphasis is placed on the interpretative framework of the person having the experience, so any experience may be deemed religious or spiritual if it is interpreted through a framework of religious or spiritual beliefs. Many qualitative researchers would query the possibility of an uninterpreted, unmediated experience and so this may be an artificial distinction. Yet Watts (2002: 91) seeks to retain a qualified version of this possibility, contending that religious experience may be 'relatively unmediated' (emphasis in original) as it 'may arise from an attempt to free oneself from the usual processes of cognitive mediation' and hence may be less subject to contextual factors than other categories of experience. This is an interesting claim, especially for qualitative researchers who are often highly contextually focused.

\section{Psychology of religion}

In recent decades, a sub-discipline has emerged within US psychology that has tried to integrate psychology and religion (and, to a much lesser extent, various types of spirituality), leading, in 1976, to the establishment of Division 36 within the American Psychological Association, devoted to the psychology of religion. ${ }^{1}$ This domain claims that it approaches religion from the standpoint of psychology, without making assumptions about religious truths and values, and considers how psychology can enrich understandings of people's religious beliefs, values and behaviours. In Britain, the psychology of religion only began to gather momentum in the 1990s. Yet the notable upsurge in publications on psychology and religion, beginning in the early part of that decade, is indicative of a shift in psychology's interest in religion in both the USA and 
Britain.

A range of issues has been explored within the psychology of religion, such as personality and other correlates of religious belief, the relationship between religious belief and behaviour, religious belief as a psychological resource in times of difficulty, the social psychology of religious cults, religious conversion and commitment, personal religious experience, the relationship between religion, mental health (and psychopathology) and well-being generally, the role of religion and spirituality in psychotherapy and the importance of social, contextual and cultural factors in religious development (see, for example, Beit-Hallahmi \& Argyle, 1997; Loewenthal, 2000; Paloutzian \& Park, 2005; Spilka et al., 2003). Much of this research has been conducted within a positivist-empiricist framework, using orthodox designs and quantitative methods. This emphasis on quantitative work has occurred even when the positivistempiricist framework does not seem to fit comfortably with the research topic, as in research on religious, spiritual and mystical experiences (see Hood's, 1975, 'mysticism scale', for example). It could be claimed that this emphasis on the positivist-empiricist framework and quantitative analysis is not surprising, given the historical tensions between religion and psychology and the consequent need for the psychology of religion to establish 'scientific' credibility. Also qualitative research has only moved from the margins of British psychology in recent decades (to different extents in different branches of the discipline) and this process is unfolding even more slowly in the USA. Yet quantitative analyses continue to dominate the psychology of religion today. For example, in 2006, of the 35 data-based articles that appeared in three major journals focusing on the psychology of religion in the USA and the UK (International Journal for the Psychology of Religion, Journal of Psychology and Theology and Mental Health, Religion \& Culture), 30 offered quantitative analyses (some arising from experimental designs) and five were qualitative.

Of course, it is unfair to complain about the dominance of traditional designs and quantitative analyses because these have often been appropriate to the questions that researchers in the psychology of religion have chosen to explore. What we might take issue with is the nature of the research questions that have been posed. It could be said that there has been a tendency to focus on the most readily researchable questions within psychology's established methodological repertoire. This has marginalized other questions, leaving them only partially examined or on the sidelines altogether, such as those involving the phenomenology of religious, spiritual or mystical experience and its implications for the intrapersonal, interpersonal and transpersonal dimensions of self - that is, questions that address non-material, non-practical aspects of spirituality. There has also been a tendency to conceptualize religious or spiritual experiences exclusively in terms of those psychological and/or psychosocial (mediating) factors that are of interest to a given study, implying that there is nothing authentically religious or spiritual about these experiences (with 'authenticity' here not seen as inimical with interpreted experience) (Mental Health Foundation, 2006; Watts, 2002). It is as if researchers are so concerned with constructing their work as unquestionably scientific and psychological that they sometimes end up producing research that is reductionist and that brackets what, for many participants, lies at the heart of the research topic.

\section{Qualitative methods in research on psychological aspects of religion and spirituality}

Given these shortcomings, there is a need to consider what the frameworks and epistemologies of qualitative methods can offer (and have provided to) research on psychological aspects of religion and spirituality. However, as is always the case when considering what qualitative methods can offer research on any topic, we need to remember that what determines the 
quality of a research study is not the method used but the appropriateness of that method to the research questions, the skill with which the method is applied and the way in which data are interpreted in light of appropriate theoretical concepts (among other considerations).

Writers on qualitative methods have associated them with various potential benefits, such as the possibility of accessing participants' meaning-making on their own terms (while acknowledging the cultural and other resources from which meaning-making is fashioned), addressing process issues and potentially focusing on context in all its complexity and fluidity (for example, see Coyle, forthcoming; Willig, 2001). These potentialities can allow new research questions to be explored about topics that have already been examined quantitatively within the psychology of religion (and spirituality) and perhaps the exploration of topics that previously have been marginalized and regarded as 'off-limits'. For example, the capacity of qualitative methods to permit the concerted exploration of contextual considerations could help in investigating Watts' (2002) contention that religious experience may be relatively unmediated.

Phenomenologically-oriented methods seem most obviously to embody these qualities and to be best placed to perform these functions. Such methods include those that are explicitly and exclusively phenomenological (Moustakas, 1994) as well as those in which participants' phenomenologies are a core consideration but where the interpretative role of the researcher is also foregrounded, such as interpretative phenomenological analysis (IPA) (Smith \& Osborn, 2003), grounded theory (Henwood \& Pidgeon, 2006) and some versions of narrative analysis (Crossley, 2000). Examples of psychologically-oriented research in which these methods are applied to questions involving religion and spirituality are readily available. Wright (2003) used a phenomenological method to explore the meaning of spirituality among African American women recovering from substance abuse; Golsworthy and Coyle (1999) employed IPA to examine how older adults used Christian beliefs in meaning-making following the death of a partner; Walton (1999) used grounded theory to discover what spirituality meant to patients recovering from an acute myocardial infarction and to identify their perceptions of the role played by spirituality in their recovery; and Murray et al. (2004) applied techniques of narrative analysis to accounts of spiritual needs provided by people with terminal lung cancer or heart failure and their carers. Wright's (2003) study consistently and vividly reports on and interprets participants' accounts of religious/spiritual beliefs and experiences from within participants' phenomenological worlds, in keeping with the study's phenomenological method. Murray et al.'s (2004) study shares this quality to a significant degree and, unlike some other narrative analyses (for example, see Lindgren's, 2005, study of Muslims' experiences of prayer), is not overwhelmed by a focus on narrative structure and function. The studies by Golsworthy and Coyle (1999) and Walton (1999) also provide a clear sense of participants' meaning-making around spirituality and religion but some reductionism is evident when religious and spiritual beliefs are conceptualized largely as coping resources.

Note, though, that a desire to foreground participants' meaning-making and avoid reductionism does not mean that participants' accounts should always be taken at face value and should not be subjected to interpretation or critical interrogation using psychological concepts and theory. For example, the nature and location of the border between accounts of some religious and spiritual experiences and 'psychotic' experiences are open to debate but some writers have tried to offer clarification (for example, see Clarke, 2001). If a qualitative researcher were analysing accounts of religious/spiritual experiences that seemed to share key elements of the construct of 'psychosis', they would be justified in acknowledging this in their interpretations. To avoid 
accusations of reductionism, depending on the research method used, we might also expect the researcher to consider and offer other interpretations (looking at, for example, the meaningfulness of what may appear to be psychotic elements) and to be critically aware of the assumptions of an interpretation in terms of psychosis. Indeed, in any qualitative study of religion or spirituality, the presentation of phenomenological interpretations (in a non-tokenistic way) alongside other critical and theoretical interpretations seems an interpretative strategy worthy of consideration.

This would present challenges for research methods founded upon a social constructionist epistemology, most obviously discourse analysis (Parker, 1992; Potter \& Wetherell, 1987; Wetherell et al., 2001), but these also have a role to play. Rather than speculating on the relationship between talk about the transcendent and/or spirituality and the actualities supposed by that talk, discourse analysis instead looks at what such talk does, that is, at the rhetorical functions it performs. This is important for research on religion and spirituality that specifically examines the role of social and cultural processes in the constitution of religious and spiritual discourses and vice versa. Social constructionist work can show how such discourses (like all others) are infused with ideological assumptions, the interests that are served and those that are marginalized by these discourses and the ways in which the discourses are used in specific contexts. For example, Roth and Alexander (1997) examined how school pupils drew upon scientific and religious discourses in talking about controversial issues such as abortion, euthanasia and the origins of humankind and considered the implications for pupils' science learning.

However, social constructionist research on religion and spirituality carries the same risk as positivist-empiricist research in that both cannot readily entertain the possibility that there is something authentically religious or spiritual about whatever topic is being explored. When applied to research questions such as those that focus on reports of religious or spiritual experience, an exclusively social constructionist approach would regard the central reported experience as having no 'reality' (whether objective or phenomenological) beyond the constructions of that experience. All is reduced to a product of social constructionist processes (but social constructionists would take issue with the description of this as 'reductionism'). Although non-social constructionist methods may find it difficult to capture the heart of the experience (as we shall see later), social constructionism would regard this quest as misplaced and would represent 'the heart of the experience' as a construct worthy of analysis in terms of rhetorical function. This is not to deny the potential value of the critical analyses that social constructionist approaches can offer psychological research on religion and spirituality. Yet it is important to consider when these approaches might most appropriately provide one set of interpretations within multiple interpretations of the same data, perhaps within what might be described as epistemological ‘bricolage’ (Denzin \& Lincoln, 2005).

\section{Effing the ineffable: can non-material religious/spiritual concepts and experience be captured in language?}

Whatever the benefits that qualitative methods with at least some phenomenological emphasis can bestow upon research on psychological aspects of religion and spirituality, there is one factor that can bedevil research on the phenomenology of non-material and non-practical religious/spiritual experience. This is the difficulty that researchers and, more pertinently, participants may have in adequately expressing non-material religious/spiritual concepts and experiences in language. While non-material religious or spiritual experiences may belong to the category of the non-discursive and so are inarticulable as they occur and perhaps immediately 
afterwards (see Frosh, 2002, on this category), even fashioning clear accounts of these experiences retrospectively may prove difficult. As qualitative research methods are heavily reliant on linguistic data, this may be a serious concern.

The potential difficulty of capturing religious/spiritual concepts and (particularly) experiences within language is not simply concerned with the potential social awkwardness or embarrassment that such talk may cause in a largely secular culture. Even those who have religious or spiritual commitments or who work with religious or spiritual ideas can find it difficult to put these ideas and related experiences clearly into words. In recent years, several doctoral trainees in Counselling Psychology at the University of Surrey have, under my supervision, conducted qualitative research on various spirituality-related topics (the studies quoted here are by Lynne Gravell, 2007, Iliana Stamogiannou, 2007, and Valerie Suarez, 2005). In this research, interviewees were asked about their understanding of spirituality and they repeatedly responded by emphasizing how difficult it was to define the term. In one study, some therapy clients expressed the view that words inevitably reduced spirituality to rational explanations, intellectual understandings or banalities. As one person said:

I don't think spirituality is all about words and arguments and mindsets...I think it is much deeper than that. It is what is in my heart, what's in my soul.

As participants tried to define their spirituality, hesitation and changes of direction were common in their accounts, as was an emphasis on an unknowable, non-concrete, indefinable or uncertain quality to their spirituality, which they did not find a cause for concern:

But yeah I don't know there is something else yes and that something is 'I don't know' and I don't need to know. It's there, I have a... I s'pose I have a belief in life and the process. I am not really sure. I can't categorize it in that way but the point is I don't need to.

That's the big thing about the spiritual dimension - sort of moving away from concrete materialistic beliefs [ ] and into something which is uncertain and yet at the same time has a positive quality to it.

Even those who were willing to conceptualize their spirituality in slightly more specific terms often stressed a dimension that eluded being captured in language:

The talking about spirituality I think it was finding that and essentially that is spirituality is about connecting purely and simply and I suppose having some acceptance of an unwritten unspoken purpose. Well it doesn't have to be spoken, it doesn't have to be written - it's just there.

The difficulties reported and experienced in these studies were a far-from-original finding. For example, in Hay's (2006) study, 76 per cent of people reported having had a spiritual or religious experience. Although these were often described in terms of an awareness or experience of a generic 'god', some people had greater difficulty in capturing their experiences in words, speaking of a vague, intuited awareness of 'something' out there which defied precise explanation.

These difficulties in expression could be interpreted as pointing to a lack of familiarity with 
standard religious and (lay) theological vocabulary, a reluctance to use such vocabulary or the inadequacy of such vocabulary to describe the range of human experience of the spiritual and/or transcendent (especially when wishing to avoid traditional ideas of 'God') in a Western twentyfirst century context. Yet the difficulties are not specific to one historical or cultural setting. For example, apophatic theology has long construed God as ineffable: within this tradition, humankind is represented as being unable to describe the essence of God who is constructed as completely 'Other' and as ultimately lying beyond human knowledge. This outlook can be found within Christianity (from early in its history), Judaism, some forms of Buddhism (with caveats concerning the 'Divine') and especially in the Hindu scriptures. Although we are talking here about a tradition that constructs God's essence as ineffable, this ineffability can legitimately be said to extend (at least to some extent) to experiences of divine action and of connection/relationship with the Divine within lives. Hence, from this perspective, it would not be surprising that research participants should find it difficult to capture experiences of/related to the Divine or the transcendent in words. Rather than being attributable to contextual factors, from the perspective of apophatic theology the difficulty arises from the nature of their experiences.

In accordance with my call for multiple interpretations, a final possibility that must be acknowledged is the social constructionist/discourse analytic perspective on this. Such a perspective would consider the functions that are achieved by constructing spiritual/religious concepts and experiences as difficult to express in language or at least to express with clarity. It could be suggested that this construction positions the speaker as an insider to a mysterious and mystical realm that lies beyond the mundane everyday world of language and a possessor of privileged experience: it provides them with a social distinctiveness that may be valued in some contexts. Also, this construction could be said to protect the spiritual/religious dimension from detailed critical interrogation because the critic is given little to work with. It has even been contended that constructing particular experiences as ineffable is what enables them to be understood as spiritual or mystical: 'ineffability' is thus constitutive of the category of 'spiritual' or 'mystical’ experience (Proudfoot, 1985).

Despite professed difficulties, some people do manage to speak about past non-material spiritual/religious experiences quite eloquently and powerfully - and not only in well-known mystical writings. For example, in Suarez's (2005) research on views and experiences of integrating spirituality into psychotherapy, some therapists reported being illuminated or guided by 'the Spirit' in therapy. They described these occasions as moments of 'connection', 'spiritual intimacy', 'understanding', 'insight', 'clarity' and 'healing', in which the Spirit was said to have revealed to them what was going on in the client's heart, the nature of the client's core pain and/or what the client needed. For example, one participant described something that she interpreted in terms of a 'word from the Lord':

The image that came up for me was about her [the client] and a baby and it was completely unrelated to what she was talking about and I sort of thought about it for a long time and [ ]...I went ahead and said what comes up for me [ ] and then she sort of fell apart a little bit and it was all about an abortion [ ] and a baby that never was [ ] and it was one of those things that just convinced me that if you are having a really strong what I would call 'spiritual sense' but equally called a 'psychological sense' [ ], give it a shot and share it and preface it by saying, 'This seems to have nothing to do with what you are saying but...' and the fact that it was such - it really went to the core of what was painful for her and what was hard for her. 
This brief excerpt provides a sense of the context and of how the speaker classified this experience. Further gentle probing may have elicited accounts of what she believed was going on cognitively, affectively and transpersonally for her (and for her in interaction with the client and with the transcendent) in the moments before, during and after this experience. It is worth noting that therapists who reported these experiences acknowledged the difficulty of determining what was spiritual and what was psychological in these moments of illumination. Given that earlier we noted the possible utility of multiple interpretations in research on religious and spiritual experience, it is interesting that they themselves recognized that other therapists who did not have a spiritual interpretative framework might interpret the same phenomena in terms of high quality empathy and good therapeutic attunement.

So how can we make sense of professed difficulties in speaking about non-material spiritual/religious experiences existing alongside eloquent accounts of such experiences? It could be that some people are more practised than others at such talk and draw upon existing discourses from theology, spirituality and/or mysticism (which are many and varied, as a perusal of the 'Mind, body and spirit' section of any sizeable bookshop will reveal) to offer accounts that are located within one discourse or that draw upon several. However, sometimes in the data sets mentioned above, the same participant would profess difficulty early in the interview but would later offer an elaborated account of their spirituality and spiritual experiences. In a context where participants may initially have been uncertain about the interviewers' stance towards spirituality, their initial accounts of their spirituality may have been hesitant and tentative to avoid committing themselves to a position from which they may have wanted to retreat if it had been met with any sign of disapproval from the interviewers. Once the safety of the interview context was ascertained, participants may have felt more comfortable in speaking with greater commitment and clarity about their experiences and positions. Yet this pattern was by no means a universal one: some participants continued to speak in hesitant and tentative terms throughout their interviews. This could indicate that these participants never felt comfortable within the interviews (an unlikely scenario as the interviewers' performance was routinely monitored closely and all interviewers were trainee Counselling Psychologists, skilled in sensitive interactions) or it could provide further evidence of the at least partial ineffability of some spiritual and religious concepts and experiences.

How then might a qualitative researcher, seeking to investigate psychological aspects of religious or spiritual experiences, respond to these difficulties? The aim of this article was primarily to outline these difficulties and encourage creative methodologists to continue exploring possibilities for accessing non-material, religious and spiritual experiences and analysing them in ways that are psychologically useful and non-reductionist. This may involve moving beyond the accepted repertoire of qualitative psychology. For example, Heron (1998) has advocated what he describes as 'long-term lived inquiry', complemented by short-term cooperative inquiry, involving profound, sustained, critical, individual reflection on and engagement with the spiritual. However, although the research process involves working reflectively with others, Heron holds that the warrant of such inquiry is limited primarily to the individual, which would leave many qualitative psychologists sceptical about its utility. I myself have no easy solutions to the research challenges that I have identified. Nonetheless, while risking an anti-climactic denouement, I wish to offer a reminder about the value of skilfullyhandled interviews and a suggestion about the potential value of non-verbal data. 
and interviewee as a means of creating a facilitative and respectful research context in which to explore issues that can be difficult to verbalize. If a participant finds it difficult to talk about religious/spiritual concepts or experiences because they feel awkward, embarrassed and wary of being judged, the establishment of good rapport between the interviewer and the participant (involving the communication by the interviewer of a supportive, sympathetically understanding and facilitating stance towards the interviewee) may prove helpful. Even if the difficulty arises because the essence of the focal issues is not easy to convey within language, good rapport can encourage the participant to grapple with this problem. A sensitive and empathic qualitative interviewer can convey an acceptance of hesitations and circuitous reflections and a willingness to wait patiently until the interviewee produces an account of their experiences that at least provides some (mediated) approximation (or even some distant echo) of the essence of those experiences. Although this emphasis on good rapport is hardly novel, researchers can feel illequipped to explore the phenomenology of religion and spirituality, especially if they are 'outsiders' to the domain and are unfamiliar or uncomfortable with the discourses in terms of which participants may frame their accounts. Hence it is useful to remind researchers that many of the challenges they may experience can be at least partly addressed by the careful use of standard research interviewing skills.

In addition, researchers may consider methods of data generation that are non-verbal, at least at the outset (see Braud \& Anderson, 1998). For example, they may invite participants to try to convey religious/spiritual concepts or experiences through drawing or painting, perhaps following this with an invitation to discuss the foci of the artwork. Indeed, a participant in Suarez's (2005) study reflected on how such an approach had been used in her psychotherapy:

We did a lot of art work and clay work and this kind of thing and one of the things [ ] was actually a drawing of what my soul looked like. [ ] I had never been asked [to do] that before and had no idea but I drew something the way you do with these things and it completely mirrored what was...happening for me on the inside.

The analysis of non-verbal data presents challenges for psychological researchers owing to the paucity of guidance within the discipline (except in quite specific contexts, such as the analysis of children's drawings within developmental psychology). Yet, material on analysing visual data has begun to appear within qualitative psychology (for example, see Frith et al., 2005) and ideas may also be gained from other disciplines where such analysis is better established (anthropology, for example).

\section{Conclusion}

Rowan (2001: 8) has claimed that 'much of human experience' - and perhaps especially some religious/spiritual concepts and experiences - lies beyond the reach of research, which he sees as 'dedicated to the conscious world'. Researchers conducting work on religious/spiritual concepts and experiences certainly need to understand what may be the (professed) limits of what participants can say about some of these concepts and experiences. Yet pessimism about research potentialities in this domain is premature. While currently available 'mainstream' qualitative research approaches can sometimes struggle, it remains to be seen whether acceptable and credible approaches will be developed which can more readily access the heart of these concepts and experiences and increase researchers' willingness to address them. However, methodological creativity needs to be accompanied by a preparedness to view data through interpretative frameworks that take religious, spiritual and theistic dimensions seriously (however that is defined). Such developments would prove invaluable in helping to accord non-material, 
religious/spiritual concepts and experiences a more central, less marginalized position within the psychology of religion and spirituality.

\section{References}

Beit-Hallahmi, B. and Argyle, M. 1997: The psychology of religious belief, behaviour \& experience. London: Routledge.

Belzen, J.A., editor, 2000: Aspects in contexts: studies in the history of psychology of religion. Amsterdam/Atlanta, GA: Rodopi.

Braud, W. and Anderson, R., editors, 1998: Transpersonal research methods for the social sciences: honoring human experience. Thousand Oaks, CA: Sage.

Clarke, I. 2001: Psychosis and spirituality: the discontinuity model. In Clarke, I., editor, Psychosis and spirituality: exploring the new frontier. London: Whurr, 129-42.

Coyle, A. 2007: Introduction to qualitative psychological research. In Lyons, E. and Coyle, A., editors, Analysing qualitative data in psychology. London: Sage, 9-29.

Crossley, M. 2000: Introducing narrative psychology: self, trauma and the construction of meaning. Buckingham: Open University Press.

Denzin, N.K. and Lincoln, Y.S. 2005: Introduction: the discipline and practice of qualitative research. In Denzin, N.K. and Lincoln, Y.S., editors, The SAGE handbook of qualitative research. Thousand Oaks, CA: Sage, 1-32.

Eagleton, T. (2007): The meaning of life. Oxford: Oxford University Press.

Elkins, D.N., Hedstorm, L.J., Hughes, L.L., Leaf, J.A. and Saunders, C. 1988: Towards a humanistic-phenomenological spirituality. Journal of Humanistic Psychology 28(4), 518.

Emmons, R.A. 1999: The psychology of ultimate concerns: motivation and spirituality in personality. New York: Guilford Press.

Frith, H., Riley, S., Archer, L. and Gleeson, K. 2005: Imag(in)ing visual methodologies, editorial. Qualitative Research in Psychology 2, 187-98.

Frosh, S. 2002: After words: the personal in gender, culture and psychotherapy. Basingstoke: Palgrave.

Golsworthy, R. and Coyle, A. 1999: Spiritual beliefs and the search for meaning among older adults following partner loss. Mortality 4, 21-40.

Gorsuch, R.L. and Miller, W.R. 1999: Assessing spirituality. In W.R. Miller, editor, Integrating spirituality into treatment: resources for practitioners. Washington, DC: American Psychological Association, 47-64.

Gravell, L. 2007: A portfolio of academic, therapeutic practice and research work including an investigation into the spiritual and psychological development of a former alcoholic. Unpublished Practitioner Doctorate (PsychD - Psychotherapeutic and Counselling Psychology) portfolio: University of Surrey.

Hay, D. 2006: Something there: the biology of the human spirit. London: Darton, Longman \& Todd.

Henwood, K. and Pidgeon, N. 2006: Grounded theory. In Breakwell, G.M., Hammond, S., FifeSchaw, C. and Smith, J.A., editors, Research methods in psychology, third edition. London: Sage, 342-64.

Heron, J. 1998: Sacred science: person-centred inquiry into the spiritual and the subtle. Rosson-Wye: PCCS Books.

Hood, R.W. 1975: The construction and preliminary validation of a measure of reported mystical experience. Journal for the Scientific Study of Religion 14, 29-41.

Lindgren, T. 2005: The narrative construction of Muslim prayer experiences. International 
Journal for the Psychology of Religion 15, 159-74.

Loewenthal, K.M. 1995: Religion and mental health. London: Chapman \& Hall.

Loewenthal, K.M. 2000: The psychology of religion: a short introduction. Oxford: Oneworld.

Mental Health Foundation 2006: The impact of spirituality on mental health: a review of the literature. London: Mental Health Foundation.

Moustakas, M. 1994: Phenomenological research methods. Thousand Oaks, CA: Sage.

Murray, S.A., Kendall, M., Boyd, K., Worth, A. and Benton, T.F. 2004: Exploring the spiritual needs of people dying of lung cancer or heart failure: a prospective qualitative interview study of patients and their carers. Palliative Medicine 18, 39-45.

Paloutzian, R.F. and Park, C.L., editors, 2005: Handbook of the psychology of religion and spirituality. New York: Guilford Press.

Parker, I. 1992: Discourse dynamics: critical analysis for social and individual psychology. London: Routledge.

Potter, J. and Wetherell, M. 1987: Discourse and social psychology: beyond attitudes and behaviour. London: Sage.

Proudfoot, W. 1985: Religious experience. Berkeley, CA: University of California Press.

Roth, W.-M. and Alexander, T. 1997: The interaction of students' scientific and religious discourses: two case studies. International Journal of Science Education 19, 125-46.

Rowan, J. 2001: Counselling psychology and research. Counselling Psychology Review 16(1), 78.

Rowan, J. 2003: Counselling psychology practice: a transpersonal perspective. In Woolfe, R., Dryden, W. and Strawbridge, S., editors, Handbook of counselling psychology, second edition. London: Sage, 221-40.

Smith, A. 2006: Why is the Church not facing up to the spirituality revolution? Renew: Newsletter of Catholics for a Changing Church No. 140, 3-4.

Smith, J.A. and Osborn, M. 2003: Interpretative phenomenological analysis. In Smith, J.A, editor, Qualitative psychology: a practical guide to research methods. London: Sage, 5180.

Spilka, B., Hood, R.W., Hunsberger, B. and Gorsuch, R. 2003: The psychology of religion: an empirical approach, third edition. New York: Guilford Press.

Stamogiannou, I. 2007: A portfolio of academic, therapeutic practice and research work including an exploration of psychologists' and clients' experiences of addressing spirituality in cognitive-behavioural therapy. Unpublished Practitioner Doctorate (PsychD - Psychotherapeutic and Counselling Psychology) portfolio: University of Surrey.

Suarez, V. 2005: A portfolio of academic, therapeutic practice and research work including an investigation of psychotherapists' and clients' accounts of the integration of spirituality into psychotherapeutic practice. Unpublished Practitioner Doctorate (PsychD - Psychotherapeutic and Counselling Psychology) portfolio: University of Surrey.

Tacey, D. 2004: The spirituality revolution: the emergence of contemporary spirituality. Hove: Brunner-Routledge.

Walton, J. 1999: Spirituality of patients recovering from an acute myocardial infarction: a grounded theory study. Journal of Holistic Nursing 17(1), 34-53.

Watts, F. 2002: Theology and psychology. Aldershot: Ashgate.

Wetherell, M., Taylor, S. and Yates, S.J., editors, 2001: Discourse theory and practice: a reader. London: Sage.

Willig, C. 2001: Introducing qualitative research in psychology: adventures in theory and 
method. Buckingham: Open University Press.

Woodhead, L. and Heels, P. 2004: The spiritual revolution: why religion is giving way to spirituality. Oxford: Blackwell.

Wright, V.L. 2003: A phenomenological exploration of spirituality among African American women recovering from substance abuse. Archives of Psychiatric Nursing 17, 173-85.

Zinnbauer, B.J., Pargament, K.I., Cole, B., Ryle, M.S., Butter, E.M., Belavich, T.G., Hipp, K.M., Scott, A.B. and Kadar, J.L. 1997: Religion and spirituality: unfuzzying the fuzzy. Journal for the Scientific Study of Religion, 36, 549-64.

1 Note that these and subsequent observations refer specifically to the domain which has become known as the psychology of religion in recent decades. Spiritual and religious writings have long addressed psychological aspects of spirituality and religion, drawing upon individual cases. Also, mindful of the observations made in this article about the relative paucity of qualitative studies in the psychology of religion, it is important to note that sociological and anthropological research on religion is characterized by greater methodological diversity. 